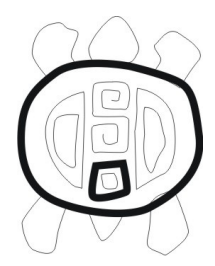

RMA

Antropología Social

\title{
Tiempo y ritual. Una aproximación al análisis de las representaciones del orden en la sociedad colonial (Gobernación del Tucumán, siglos XVII y XVIII)
}

Silvina Smietniansky

\author{
CONICET, Universidad Nacioanl de Quilmes y \\ Universidad de Buenos Aires. E-mail: ssmietniansky@unq.edu.ar
}

\begin{abstract}
Resumen
Este trabajo de carácter exploratorio constituye una primera aproximación al análisis de las experiencias y los sentidos del tiempo implicados en las representaciones del orden social, según lo han vivido y significado los vecinos y los funcionarios de gobierno en Indias durante el período colonial. Nos proponemos desarrollar un estudio comparativo de las instituciones del cabildo y los juicios de residencia, basado en el examen de un conjunto de documentos de gobierno y justicia relativos a la gobernación del Tucumán durante los siglos XVII y XVIII y organizado a partir de dos interrogantes centrales. Por un lado, interesa abordar cómo se configuraban y articulaban dos experiencias del tiempo diversas -un tiempo local y cotidiano y, otro tiempo que denominamos regio y ritual-; y por otro lado, exploramos de qué manera el carácter tradicional y formalizado de las prácticas que los cabildantes y los participantes del juicio de residencia desarrollaban en los contextos institucionales, contribuía a construir una representación del orden social figurado de gran estabilidad y anclado en un tiempo de larga duración.
\end{abstract}

Palabras clave: tiempo; ritual; cabildos; juicio de residencia; Tucumán colonial

Time and ritual. An approach to the analysis of the order representation in colonial Tucumán's society (Gobernación del Tucumán, XVII-XVIII centuries)

\begin{abstract}
This exploratory work constitutes an approach to the analysis of time experiences y meanings that were implies in social order representation according to the lives and perspectives of the vecinos and government functionaries in Indias during the colonial period. We intend to develop a comparative study of the cabildo and juicio de residencia institutions, based on the exam of a set of government and justice documents relative to the Tucumán province during XVII and XVIII centuries, and organized upon to tow central questions. On one side, we are interested on how two different time experience - a local and ordinary time, and another time that we called regal and ritual- were configured and articulated; and on the other side, we explore in which way the formal and traditional character of the practices that were performed by the cabildantes and the juicio de residencia participants in the institutional contexts, contributed to elaborate a representation of the social order characterized for its great stability and long lasting existence.
\end{abstract}

Keywords: time; ritual; cabildos; juicio de residencia; colonial Tucumán

Sabemos que cada sociedad construye y concibe de manera diferente aquello que nosotros definimos con la categoría de tiempo, y esta diversidad queda reflejada al comparar trabajos que han atendido a culturas y contextos históricos distintos ${ }^{1}$. En la construcción social del tiempo, en su representación y su experiencia, los rituales asumen un papel central dado que marcan los ritmos y los ciclos de la sociedad que alterna entre las actividades profanas y las sagradas; entre el tiempo cotidiano y el tiempo extraordinario de los festejos y conmemoraciones (Durkheim 2007; Durkheim y Mauss 1971; Leach 1971). De manera que el tiempo puede medirse a partir de los lapsos que restan entre la celebración de uno y otro

\footnotetext{
1 Véase Durkheim (2007), Durkheim y Mauss (1971), Evans-Pritchard (1979), Thompson (1984) y Todorov (1982), entre otros.
}

ritual. Pero además la singularidad de los rituales reside en que su dimensión formalizada -en el sentido de que su estructura se mantiene estable a lo largo del tiempoaporta a la representación de que el contenido trasmitido es tradicional e inmutable (Tambiah 1985). Si el tiempo implica el transcurrir -sea cíclico, lineal o pendular- y la historia el cambio, los rituales tienen la potencialidad -no quiere decir que sea siempre así- de construir la significación opuesta.

Este trabajo se propone analizar qué características singulares asumía la noción y la experiencia del tiempo en relación con la representación del orden colonial desde la perspectiva de los vecinos y los funcionarios del gobierno hispano en Indias. Para ello nos basamos en el examen de dos instituciones, los cabildos y los juicios de 
residencia, cuyas respectivas estructuras se mantuvieron estables a lo largo del extenso período y territorio colonial. Los cabildos constituían el gobierno local de la ciudad y su jurisdicción, y cumplían múltiples tareas de índole política, económica y social en el regimiento de la vida de sus habitantes, mientras que el juicio de residencia era un procedimiento ordenado por la autoridad regia que intervenía el terreno del poder local aproximadamente cada diez años, y cuyo fin consistía en evaluar la labor de gobierno de los funcionarios, sancionarlos si hubieran incumplido sus funciones y contribuir a la mejora de la instituciones. Nuestra perspectiva de análisis focaliza en la dimensión ritual de ambas instituciones y aborda la estructura formal en que tales prácticas se conducían, entendiendo que no eran una simple forma de hacer las cosas, sino que esa manera singular-tradicional, estable a lo largo del tiempo, repetitiva y redundante- tenía efectos más allá de los fines concretos que perseguían². Tenían la capacidad de representar y construir el orden político del que eran parte ${ }^{3}$.

Entendemos que un examen conjunto y comparativo de los cabildos y las residencias en el marco de la Gobernación del Tucumán para los siglos XVII y XVIII puede contribuir a desandar dos interrogantes que hemos elaborado a partir de los dos problemas planteados en el primer párrafo con respecto al estudio de los rituales y su relación con la construcción social del tiempo. Por un lado, partiendo de la conceptualización de la residencia como ritual interesa describir y rastrear las prácticas que configuraban su duración como un tiempo extraordinario, impuesto desde los intereses y los ritmos de la metrópoli. En el contexto local la sustanciación de este procedimiento de control que convocaba de manera más o menos activa a toda la población de la gobernación

\footnotetext{
2 El abordaje de los cabildos y las residencias a partir del concepto de ritual no supone una aplicación inmediata e instrumental de las teorías a las cuales apelamos. En otros trabajos (2007, 2009 y 2010) discutimos el andamiaje teórico a partir del cual estudiamos de la dimensión ritual del poder de las instituciones del gobierno colonial. A los efectos de este artículo creemos importante destacar que en la construcción de nuestra perspectiva teórica recuperamos en particular los aportes de Leach (1976), Tambiah (1985) y Turner (1999). La noción de dimensión ritual remite al aspecto expresivo o comunicativo de una acción, que trasciende la finalidad técnica de la misma (Leach 1976). Pero los rituales no se limitan a comunicar un mensaje, sino que en ese mismo decir producen la realidad de la cual son parte y en ese sentido pueden considerarse actos performativos (Tambiah 1985). Por otro lado, el estudio de los rituales demanda atender tanto a su capacidad para cohesionar y mantener el orden social, como a los usos que hacen los propios participantes y los conflictos que en el contexto ritual se despliegan (Turner 1999). Sobre el uso y nociones del concepto de ritual en antropología puede consultarse los trabajos de Díaz Cruz (1998), Peirano (2001), Falk Moore y Myerhoff (1977) y Goody (1961).

3 Esta mirada que ilumina sobre la capacidad de los rituales para aportar a la reproducción del orden social no soslaya el hecho de que ambas instituciones constituyeron espacios de conflicto en que se enfrentaron las facciones de las élites locales y éstas con el poder regio. Esa dimensión conflictiva que otorga otro dinamismo y variabilidad a la estructura formal de los cabildos y las residencias no será abordada en este artículo. Para el caso de las residencias un análisis de esta clase se encuentra en Smietniansky 2010.
}

del Tucumán perturbaba los ritmos cotidianos. Como contra cara de ese tiempo ritual en nuestro estudio la cotidianeidad se visualiza entonces a través del conjunto de actividades que componían la rutina de los cabildos. De esta manera, al abordar ambas instituciones pretendemos aproximarnos a dos experiencias del tiempo diversas que están ancladas en dos instituciones diferentes: un tiempo que denominamos regio y ritual y, otro tiempo al que habremos de llamar local (y cotidiano). Esta primera distinción analítica que proponemos no debe hacernos olvidar que eran los mismos funcionarios del cabildo y los vecinos de la ciudad quienes daban cuerpo a una y otra institución, y por lo tanto debemos estar atentos a no deslindar las experiencias del tiempo de la práctica y la agencia de dichos actores.

En esta propuesta de abordaje y ya en este primer interrogante subyace el supuesto de que para aproximarnos a cómo el tiempo era entendido y construido por los actores es preciso atender al orden de las prácticas sobre el cual las experiencias del tiempo se fundaban. Esta perspectiva teórica que afina nuestra mirada sobre determinados fenómenos se nutre del análisis de EvansPritchard sobre la relación que los nuer establecen entre la noción de tiempo y las actividades diarias y los ciclos productivos y migratorios, concluyendo que para este pueblo del Sudán "el tiempo es una relación entre actividades" (1979: 117). Opuesta a la noción abstracta de tiempo propia de occidente, desde la perspectiva de los nuer el tiempo no se circunscribe en días, meses y años, sino que la identificación de un hecho se realiza al vincularlo con otros acontecimientos. Leach (1971) también recala en este aspecto al comparar nuestra noción de tiempo que supone una regularidad susceptible de ser medida, con aquélla de los "pueblos primitivos" anclada en el ciclo anual de las actividades económicas. Este rodeo etnográfico sirve para formular nuestra entrada a un terreno tan abstracto como es el problema del tiempo y que se complejiza puesto que nos interesa tratar de recuperar las experiencias y los sentidos del tiempo para los protagonistas de un contexto histórico lejano al nuestro a través de documentos escritos de carácter institucional. En ese sentido, la teoría y los trabajos etnográficos nos ayudan a reflexionar sobre qué trazos de ese mundo social cabe atender en nuestro intento de aproximarnos a la perspectiva de los actores.

El segundo interrogante que guía este trabajo consiste en abordar de qué manera el carácter altamente formalizado de las prácticas que los cabildantes y los participantes del juicio de residencia desarrollaban en el marco de ambas instituciones, contribuía a construir una imagen del orden social y de sus diferentes cuerpos políticos anclado en un tiempo de larga duración donde ese orden se visualizaba de gran estabilidad. En la formulación de este problema recuperamos también las ideas de Tambiah (1985) sobre la viabilidad de realizar un análisis estructural sobre la forma y un análisis sobre el contexto cultural como parte 
del mismo abordaje, lo que nos permitirá atender a cómo la forma del ritual es constitutiva de la "cosmología" que éste transmite. Analíticamente distinguimos por un lado, la estructura de los juicios de residencia y de los cabildos, y por otro, lado los valores y creencias vinculados al orden social que dichas formas tenían la capacidad para vehiculizar ${ }^{4}$. Siguiendo la perspectiva de Tambiah, diríamos que esa forma tradicional y estable a lo largo del tiempo imprimía estos mismos caracteres sobre la cosmología (para usar el término del autor) que era transmitida. Este artículo pretende centrarse sobre un aspecto de ese 'contenido', aquél que refiere a la dimensión temporal del orden social que era representado en el ritual de la residencia y en las prácticas altamente formalizadas de los cabildos. ¿Cómo la forma repercutía sobre la manera en la cual los participantes de la residencia y los funcionarios concejiles se representaban la dimensión temporal del orden social del que dichas instituciones eran parte? ¿qué características asumía la noción de tiempo y cómo eran significados los cambios en el contexto de instituciones tan formalizadas y tradicionales? Para avanzar en las respuestas a estas preguntas un análisis en el nivel de las prácticas que recala en cómo se llevaban a cabo las residencias y las actividades del cabildo, se verá complementado con el examen de un conjunto de categorías nativas que registramos en el estudio de los cabildos y que da indicios que desde la perspectiva de los actores la permanencia y la tradición asumían un valor positivo.

Con el objetivo de comenzar a desandar los dos interrogantes planteados este trabajo se basa en el examen de tres tipos de fuentes, relativas a la gobernación del Tucumán. En primer lugar, nos ocupamos del expediente surgido del juicio de residencia instruido a un gobernador en la segunda mitad del siglo XVIII. En segundo lugar, atendemos a las actas capitulares para las ciudades de Córdoba y Santiago del Estero en las cuales han quedado asentados los temas y debates desarrollados en las sesiones de los respectivos ayuntamientos. Y por último, exploramos una serie de pleitos en que los cabildos o algunos de sus miembros se vieron comprometidos por cuestiones de índole del ritual. El primer corpus documental nos permite abordar el problema del tiempo para el caso de las residencias, mientras que los otros dos componen la vía de entrada al cabildo.

La información con que contamos para el caso de las residencias es más limitada y sólo nos permite analizar el nivel de las prácticas. Su estudio, por un lado, focaliza sobre aquello que podríamos denominar el tiempo interno de este proceso jurídico. El juicio de residencia

\footnotetext{
4 En trabajos anteriores (2007, 2009 y 2010) abordamos esta imbricación entre forma y contenido, y la capacidad de los cabildos y las residencias para trasmitir ciertos principios fundantes de la monarquía española y construir el orden colonial. Véase también Herzog (2000) para el caso de las residencias en Quito y Guevara Gil y Salomon (1994) para el caso de las visitas de indios.
}

se instruía a todos los funcionarios - desde virreyes hasta cabildantes- en todo el dominio español, y en el caso de las residencias incoadas a los gobernadores éstas también se ocupaban de evaluar la labor de los miembros de los cabildos. Durante los dos meses que duraba su celebración los funcionarios concejiles y los vecinos de cada ciudad seguían un ritmo similar de actividades que perturbaba los tiempos y labores cotidianas, viéndose involucrados en un mismo y único acontecimiento que alcanzaba a la gobernación en su conjunto. En ese sentido hablamos de un tiempo ritual que comprendía todo el proceso de sustanciación de la residencia. Por otro lado, una segunda dimensión de análisis focaliza y se interroga sobre la continuidad que la estructura de las residencias mantuvo a lo largo del período colonial y en el extenso territorio indiano.

Para el caso de los cabildos y a partir de los tipos de fuentes consignados, su examen atiende a tres dimensiones de análisis, dos situadas en el nivel de las prácticas y una tercera centrada en las categorías nativas. Por un lado, puede considerarse el ritmo cotidiano del cuerpo capitular que estaba marcado por las actividades rutinarias de sus miembros y que quedó registrado en las actas que documentaban lo acontecido en las sesiones. Podríamos hablar del tiempo cotidiano del autogobierno municipal, sobre el cual (por una cuestión de espacio) sólo habremos de describir algunos de sus componentes a modo de ejemplo. Por otro lado, cabe considerar el extenso período temporal en que se mantuvo la institución de los cabildos y el hecho de que las prácticas comprendidas en el funcionamiento de los mismos presentaban un alto grado de formalización, permaneciendo relativamente inalteradas durante el dominio colonial. Por ejemplo, la apertura, el desarrollo y la conclusión de las sesiones tenían pautas que se mantuvieron al menos hasta el siglo XVIII inclusive. Este hecho marca una continuidad entre el cabildo del 'presente' con aquél que se instituyera desde la fundación de cada ciudad.

La tercera dimensión de estudio para abordar la institución capitular se establece a partir del examen de un conjunto de términos nativos a los cuales apelaban los actores para defender la legitimidad de sus acciones. Costumbre, tiempo inmemorial, estilo, práctica estilada, entre otros términos que aparecen siempre asociados en los documentos, indican que la aceptación y legitimidad de una práctica determinada estaba dada a partir de su permanencia y estabilidad a lo largo del tiempo. Esta otra mirada sobre el corpus documental se interroga sobre lo que los funcionarios capitulares decían respecto de sus prácticas, del funcionamiento del propio cabildo y del orden social y temporal en que tales prácticas e instituciones de gobierno se inscribían. A nuestro entender, este tipo de datos y esta otra dimensión en el análisis del tiempo compone una vía para aproximarnos a la perspectiva de los actores, puesto que en este registro se hace más notoria una representación del orden 
municipal como si acaso hubiera permanecido o debiera permanecer sin cambios en el transcurso de su existencia.

Es importante mencionar que este trabajo está inserto en una investigación más amplia y que asume un carácter exploratorio por cuanto nos introducimos en una nueva problemática de estudio que hasta el momento no habíamos abordado. Resulta así un espacio fértil para desarrollar y sistematizar algunas de las observaciones, ideas y preguntas que han surgido en el trayecto de nuestra investigación. En ese sentido, nos arriesgamos a 'jugar' con las herramientas conceptuales y las fuentes documentales de que disponemos como una vía para afinar las preguntas de investigación, ensayar algunas respuestas y discernir posibles perspectivas de análisis o rumbos de indagación sobre el problema del tiempo en relación con la constitución y la representación del orden colonial.

\section{Los tiempos regios}

La celebración de las residencias asumía las facultades de un ritual en el sentido de que se trataba de un acto con un alto grado de formalización, tradicional, con escasos límites para innovar en sus formas y cuya celebración instituía un tiempo y un espacio distintos al orden cotidiano. Un aspecto particular de la residencia es que ese tiempo diverso y extraordinario que recreaba estaba impuesto por los intereses y los ritmos de la metrópoli. La residencia era un procedimiento instruido por el poder regio que tenía el fin de evaluar la labor de los funcionarios de gobierno -de todos los rangos- una vez que hubieran concluido con su gestión, y sentenciarlos en caso de comprobarse delito o contravención en el ejercicio de sus funciones. Asimismo, tenía la función de registrar las falencias de gobierno, subsanarlas y mejorar las instituciones ${ }^{5}$. Se realizaban en el lugar donde el funcionario había desempeñado su cargo y tenía una duración de sesenta días. El tiempo de la residencia asumía un carácter efímero de manera que la investidura del juez de residencia o la nominación de ciertos espacios físicos (ej. las casas capitulares) como juzgado de residencia quedaban sin efecto pasado el período estipulado por la cédula real que sancionaba la apertura de cada juicio.

En un contexto de avance de la política borbónica y signado por la conflictividad local se llevó a cabo la residencia al gobernador Juan Manuel Fernández Campero. Ésta quedó documentada en un expediente de 3500 fojas y se ocupó no sólo de juzgar la conducta de este gobernador sino también de todos aquéllos que ocuparon cargos en los cabildos de las ciudades tucumanas durante el período de mandato, entre

\footnotetext{
5 Sobre los orígenes y la historia del juicio de residencia en España véase: García Valdeavellano (1963), Garriga (1991) y González Alonso (1978). Para el territorio americano, la obra clásica más importante es la de Mariluz Urquijo (1952).
}

1764 y $1769^{6}$. Esto implica que esta residencia posó su lente sobre la gestión cotidiana y local del gobierno, poniendo en escena a la élite local, cuyos miembros actuaron en calidad de imputados, testigos, magistrados y funcionarios de justicia. En septiembre de 1775 esta distante región del dominio ultramarino español se vio sacudida con los preparativos que vaticinaban el inicio de un nuevo juicio de residencia, después de 10 años del último proceso instruido al gobernador Martínez de Tineo. El arribo de la cédula real para dar inicio a la residencia, el nombramiento del juez superior, las indicaciones sobre cómo conducirse, el intercambio de misivas por consultas legales y el nombramiento de jueces subdelegados, fueron marcando el terreno del inminente acontecimiento. Aunque obviamente no constan en el expediente, casi pueden escucharse los murmullos que circulaban entre los vecinos de las ciudades, especialmente de aquéllos que acostumbrados a administrar la justicia y el gobierno local serían ahora objeto de indagación por parte de un magistrado superior. Los pregones que simultáneamente se dieron en la plaza pública de cada ciudad y que fueron reproducidos en los lugares distantes de la jurisdicción se ocuparon de comunicar a toda la población el pronto inicio de la residencia, a la cual habrían de ser llamados como testigos (si su condición social y prestigio lo permitía) o podrían demandar si hubieren sido agraviados. Así un nuevo tiempo y un nuevo espacio se iban instaurando. El ritual ya había dado comienzo.

Podemos inferir que la celebración de la residencia operó entonces perturbando los ritmos de las labores cotidianas y convocó a los moradores de las siete ciudades tucumanas en la participación (de forma, más o menos activa) de este único acontecimiento. El juez superior radicado en Córdoba nombró jueces subdelegados para el resto de las ciudades, de manera que el juicio se sustanció simultáneamente en toda la gobernación. Por un período de dos meses cada una de las ciudades -especialmente sus cabildos, donde se desarrollaba el juicio- era escenario de un mismo proceso de actividades, que incluía el establecimiento del juzgado de residencia, la publicación de edictos y listados de residenciados, toma de testimonios a los testigos, requisas en los archivos e instalaciones de gobierno, etc. La celebración aproximadamente cada diez años de un juicio de residencia le otorgaba a su dimensión temporal otros sentidos que se construían a partir del contraste con los tiempos y las actividades diarias. Si bien la residencia era resignificada y en parte modelada por los intereses y conflictos que motivaban las acciones de sus participantes en el contexto local, la fecha en que se llevaría cabo, la designación del magistrado, su duración, etc. eran elementos fijados desde la de península. Lo que a las

\footnotetext{
${ }^{6}$ Archivo Histórico Nacional de Madrid (AHN), Consejos, 20373, exp. 1. La residencia a Campero puede tomarse como base para un estudio de caso, dado que las estructuras de las demás residencias eran similares; respondían al mismo formato.
} 
élites locales les quedaba era sujetarse a esas formas, y en todo caso tratar de sacar el mejor provecho sin rebelarse abiertamente contra las facultades inquisitivas de la autoridad representante del rey.

La interpretación que proponemos sobre la capacidad de la residencia para alterar los ritmos locales y configurar un tiempo distinto al cotidiano no surge de manera 'evidente' en el documento. Es a partir del reconocimiento de los contextos locales y de la relación analítica que marcamos entre las prácticas y, la experiencia y representación del tiempo, que nos es posible inferir la significación que asumía la residencia; y que, asociado a ello, un cambio en el régimen de actividades vendría acompañado de una experiencia distinta del tiempo. Desde ya que esta experiencia tendría diversos alcances para los vecinos y funcionarios que efectivamente participaban del juicio y para el resto de los moradores -criollos y españoles de baja condición social, indios y castas- que si bien no asumían papeles de magistrados, abogados, imputados, etc., debían hacerse presente en los pregones públicos que informaban sobre la realización del proceso. Se trataba de sociedades situadas en la periferia del imperio español, configuradas a partir de redes sociales y clientelares que atravesaban los distintos estratos socioeconómicos, donde las élites durante el siglo XVII lograron hacerse de gran autonomía en la administración de la justicia y el gobierno local, pero que con el avance reformista a mediados del siglo XVIII veían peligrar las prebendas conseguidas hasta el momento. En ese mundo colonial donde los cabildos constituían el nicho de poder local (a diferencia de otras ciudades como Lima, Potosí y Charcas, donde los cabildos estaban sujetos a la cercana autoridad del Virrey o la Audiencia), donde unos y otros se reconocían en su interacción diaria y cara y cara, y donde el capital simbólico en forma de títulos, genealogías y cargos concejiles era clave para ingresar a las filas de las élites locales, es que se desplegaba la residencia y se hacía presente la figura y el poder del monarca. Por un lado, si la valoración social de los pares y de la comunidad en general era un requisito importante para ser reconocido y llamado vecino, difícilmente pasaría desapercibido un proceso que venía a poner en tela de juicio las actuaciones de esos autotitulados "padres de la república" -los cabildantes- (Lorandi 2000) y que recurría a las declaraciones de testigos de carácter "noble, y gentil idóneos". Por otro lado, en un territorio que era ajeno a las fastuosas entradas cortesanas que conocían las capitales virreinales o aquéllas en que residían las Audiencias, cabe inferir la importancia que asumía la residencia como una empresa de gran envergadura -movilización de recursos, de gente, de esfuerzo y tiempo, aún cuando las penas serían mínimas- que ponía en acto el poder inquisitivo y también el carácter parternalista del rey que velaba por el funcionamiento de las instituciones y el bienestar de sus vasallos?.

\footnotetext{
7 Un conjunto de estudios examina la significación que los festejos y funciones públicas de distinta índole tenían en la construcción, la
}

Esta exploración sobre la dimensión temporal de la residencia parece implicarse con el problema de la construcción de las jurisdicciones y la delimitación de los agregados sociales sobre los cuales operaba (Herzog 2000). La residencia circunscribía los límites de la jurisdicción del Tucumán de manera que marcaba la pertenencia de todos los habitantes a una comunidad sobre la cual intervenía el poder regio y que trascendía (abarcando) las ciudades. Incluso, podríamos decir que el tiempo de la residencia-como un tiempo distinto al cotidiano- interpelaba a todos los moradores de las ciudades tucumanas como vasallos comprendidos en la comunidad corporativa y más amplia de la monarquía española cuya cabeza era el rey (quien en este caso ejercía su potestad a través de la residencia).

La segunda dimensión de análisis en el estudio de la residencia remite a la permanencia que observamos en la estructura formal de este proceso jurídico. Sin subestimar los cambios que sufrió en su larga vida americana, esa continuidad en el tiempo como en el espacio surge al recorrer la literatura que se ha ocupado de esta institución y al comparar la fuente principal de nuestro trabajo con los aportes de otros autores ${ }^{8}$. Esto comprende también las actuaciones de magistrados, imputados y testigos, las cuales se condujeron dentro de ciertas formas de comportamiento y discursos estipulados. La legislación ordenaba que el proceso debía seguirse en dos etapas: la pesquisa secreta y la pesquisa pública. Aunque cabría designar a los preparativos (que instauraban el terreno en que se realizaba la residencia) como una fase preliminar y a la sentencia, que debía ser aprobada por el Concejo de Indias, como la fase de cierre. Con respecto a las etapas centrales, en la pesquisa secreta el magistrado tomaba testimonio de manera confidencial a los testigos sobre cuál había sido el accionar de los funcionarios residenciados durante el periodo en que ejercieron sus cargos. También visitaba las instalaciones de gobierno y la cárcel, y auditaba el archivo del cabildo. Recabada esta información, el magistrado levantaba los cargos contra el residenciado y éste avanzaba con su defensa. En la pesquisa pública se abría la posibilidad de que los particulares presentaran denuncias contra el funcionario residenciado, con motivo de haber sido personalmente perjudicado por éste o tener conocimiento de su mala actuación con respecto a otros sujetos. En relación con la sentencia, el juez no podía intervenir en juicios pendientes, ni volver sobre causas ya juzgadas, sino que su trabajo se limitaba a elaborar un informe sobre la buena o mala conducta del procesado. En general, las penas impuestas fueron multas de variado monto, inhabilitación

\footnotetext{
legitimación y el ejercicio del poder en Indias, especialmente considerando el problema de la ausencia física del rey. Pueden consultarse los trabajos de Osorio (2008), Cañeque (2004), Ortemberg (1999) y Bridikhina (2007).

${ }^{8}$ Véase Mariluz Urquijo (1952), Herzog (2000), Ponce (1985), Vaccari de Venturini (1974), Ponce y Vaccari de Venturini (1980), Jímenez Nuñez (1997), Phelan (1995), Lorandi (2000) y Lorandi y Smietniansky (2004).
} 
perpetua o temporaria.

Más allá de su dimensión jurídica y sus objetivos de contralor, la celebración de estos procesos actuaba comunicando un mensaje referido al orden y los valores compartidos por la sociedad: hacía presente la figura del rey, se reafirmaba su dominio sobre estos territorios y se recreaba la relación de subordinación y de poder delegado en que se hallaba el cabildo frente al monarca. Esta dimensión ritual de la residencia se relaciona con una noción particular de poder: un poder que se fundaba en la autoridad del monarca, que se entendía delegado de éste hacia sus funcionarios y que para considerarse legítimo debía constantemente hacerse visible y expresarse (Cañeque 2004). De hecho, en el marco de la residencia la figura del rey se hacía presente y se dispersaba por cada mínimo espacio y detalle de la celebración: en la circulación de las copias de la cédula real, en los actos de recibimiento de los jueces subdelegados en cada ciudad, en la instauración de cada juzgado de residencia, etc. La forma de la residencia era de esta manera parte de su contenido. Incluso, gran parte de los procedimientos que se seguían durante las residencias -juramentos, formas de publicar los edictos, acto de investidura del juez, entre otros- eran los mismos que acostumbraban realizar los capitulares en las sesiones privadas del cuerpo. La residencia potenciaba por un período de dos meses esos mismos dispositivos y los resituaba en un tiempo y espacio distintos.

Al analizar la permanencia de esta institución a lo largo del tiempo, también podemos considerar los vínculos que los propios participantes establecían entre las consecutivas residencias sustanciadas. Encontramos que en sus declaraciones se remitían a residencias anteriores, en algunos casos identificando alguna en particular y en otros casos refiriéndose en forma general a todas las sustanciadas previamente. De hecho, la segunda pregunta a la cual debieron responder los testigos con respecto al accionar del gobernador Campero y sus tenientes consistía en si éstos "hubieren hecho ejecutar lo dispuesto y mandado en otros residencias o tuvieran en ello alguna omisión"9. En el caso de La Rioja y Catamarca, por ejemplo, algunos de los problemas que los jueces registraron durante la residencia a Campero eran los mismos que habían quedado asentados en el proceso anterior (1764). Ortiz de Ocampo en Catamarca volvió sobre los pasos de su predecesor para indagar qué contenía el informe de la residencia anterior con respecto a la malversación de fondos del ramo del hospital. En La Rioja Ricardo Sosa interrogaba al procurador de la ciudad sobre por qué no había constancia de las resoluciones que hubieren tomado los jueces de residencia anteriores. Por otro lado, sí encontró variados documentos de gobierno que permitían exponer una historia riojana donde las deficiencias en las cuentas públicas fueron un problema

${ }^{9}$ AHN, Consejos, 20373, exp. 1, 27r-29v. constante ${ }^{10}$.

Los ejemplos de estos dos magistrados dan cuenta de que las particularidades de cada cabildo o comunidad local se filtraban en ese acontecimiento que abarcaba tales contextos de menor escala. Por un lado, las historias locales quedaron registradas en una historia de mayor envergadura como reflejan los expedientes de las residencias, cuya conservación estaba a cargo del Concejo de Indias. Por otro lado, el informe final de cada juez de residencia debía quedar en el archivo del cabildo, y por tanto podríamos pensar que parte de lo producido en el marco de ese tiempo y de esa instancia impuesta desde la metrópoli también resultaba inserta y resignificada en los archivos de la propia ciudad ${ }^{11}$. El problema sobre el tiempo vemos que se desplaza hacia una pregunta por la construcción de la historia y la significación que la elaboración de estos expedientes podía asumir en ese proceso tanto a escala del gobierno local como en instancias más centralizadas.

Estas historias locales daban a cada residencia un carácter único. La residencia a Campero fue un acontecimiento único que se vio atravesado por las múltiples luchas que trajo como consecuencia la aplicación del programa borbónico, algunas de las cuales se expusieron de manera abierta durante el juicio y otras se expresaron de forma implícita al ser deliberadamente silenciadas. En ese sentido, fue abierta la resistencia de los vecinos jujeños contra el juez subdelegado para que no pudiera sustanciar el juicio en dicha ciudad; sin embargo, casi ni noticias encontramos en el expediente sobre el difícil y conflictivo proceso de expulsión de los jesuitas que llevó a cabo Campero -hecho que explica en gran medida la fallida residencia jujeña-. Es probable que en un contexto de avance del poder regio sobre los poderes locales la residencia a Campero (con más motivos) fuera recibida -en el Tucumán- como un instrumento de la administración central para controlar e intervenir las instituciones que estaban en manos de las élites coloniales. Incluso dentro de esta misma residencia encontramos un abanico de variaciones entre los juicios llevados a cabo en las diferentes ciudades ${ }^{12}$. Al comparar esta residencia con otros trabajos que han abordado otros juicios sustanciados en regiones y períodos diferentes, puede decirse que los procesos a escala más amplia y los contextos locales imprimieron contenidos particulares en cada una de ellas. Por tanto ese tiempo ritual que venimos relatando supondría también un tiempo único, que se constituía en la relación entre determinados actores, en

\footnotetext{
10 Entre otros, hace referencia a un libro iniciado por el Obispo Juan de Zarricolea (1729), las observaciones del subdelegado de residencia Joseph Ambrosio Cancinos (1764) y el auto de la visita del Obispo Manuel Abad Illana (1768)

11 Incluso, en el caso riojano pareciera reconstruirse parte de la historia de los problemas que afrontaba el gobierno local.

12 Para un análisis sobre las formas particulares que asumió el juicio en las diversas ciudades y las implicancias del contexto reformista borbónico, véase Smietniansky 2010.
} 
determinados contextos y con contenidos singulares. La residencia a Campero era una más en el derrotero de estos juicios, pero era una en particular.

Cabe preguntarse si es allí -en esas singularidadesprecisamente donde la historia en tanto cambio y variabilidad se vislumbra de manera más clara. Mientras que la repetición periódica del mismo ritual y el alto grado de formalización que comprimía cómo y qué podía decirse y hacerse durante el juicio configuraban su carácter de permanencia, continuidad e invariabilidad. Es ese carácter el que sostenemos que se traspasaba o que nutría las representaciones del orden colonial. Y dado que la residencia era una institución que respondía y se insertaba en los órganos centrales de gobierno, entendemos que su análisis nos permite acceder a cómo los vecinos y funcionarios locales concebían y se hacían partícipes del orden colonial en escalas que trascendían el ámbito municipal: la jurisdicción provincial (sobre la cual operó la residencia a Campero) y la monarquía española en su conjunto (del que la provincia y sus ciudades eran parte).

\section{Los ritmos locales del tiempo}

El cabildo era la institución más local del gobierno colonial encargada de administrar y regir la ciudad y su jurisdicción. En Indias esta institución de origen castellano fue cooptada por las facciones de las élites locales y se configuró así en un cuerpo elitista, a cuyos cargos sólo podían acceder los vecinos que lograban dicha pertenencia al ser encomenderos, hacendados o poseer propiedades en la ciudad y su jurisdicción. Las castas, indios y el resto de la población urbana no calificada quedaba excluida de ejercer funciones en el cabildo, justicia y regimiento. Los alcaldes de primero y segundo voto, elegidos anualmente, eran la cabeza del cabildo y tenían a su cargo la administración de justicia en primera instancia. A los oficios capitulares les competía el cumplimiento de diversas tareas que en su conjunto hacían a la gestión del gobierno municipal: administrar la venta y el reparto de tierras, regular el comercio de mercaderías, cobro de los impuestos, organizar las fiestas cívicas y religiosas, y disponer sobre la provisión de agua, entre otras tareas ${ }^{13}$.

Las deliberaciones del cabildo en lo tocante a estos temas se desarrollaban una o dos veces por semana en el marco de las sesiones capitulares, denominadas acuerdos, y en algunos casos ha quedado el registro escrito de lo acontecido en forma de las actas del cabildo. En una lectura de las actas pertenecientes a distintos cabildos del Tucumán para los siglos XVII y XVIII lo primero que se encuentra es una permanencia en las formas en las cuales

\footnotetext{
13 Sobre los aspectos institucionales del cabildo véase Zorraquín Becú (1956) y Bayle (1952). Con respecto a la configuración de las élites coloniales y su imbricación en las instituciones del gobierno local en el contexto de la gobernación del Tucumán, pueden consultarse los trabajos de Bascary (1997), Paz (1997), Boixadós (1997 y 2004), Mata de López (2001), De la Orden de Peracca (2001), Marchionni (1999) y Saguier (1992), entre otros.
}

se conducían las sesiones del cabildo. La celebración de los acuerdos puede segmentarse en tres etapas: apertura, desarrollo y cierre. Las actas capitulares de Córdoba para mediados del siglo XVII, luego de indicar el lugar y fecha de realización, describen el siguiente inicio: "El cabo justicia y rregimiento de esta ciu ${ }^{d}$ se juntaron en su cabo E ayuntam ${ }^{\text {to }}$ como lo tiene de costumbre es a saber [se mencionan los nombres, apellidos y oficios] (...), y estando para tratar cossas de su rrepu ${ }^{c a} . . . " 14$. Por ejemplo, más de un siglo después, encontramos en las actas editadas de Santiago del Estero una apertura de la sesión muy similar a la anterior: "aviendonos juntado en esta sala capitular a son de campana tañida, como lo havemos de usso y costumbre a tratar y conferir, las cosas tocantes al pro, y util de esta republica, sus vecinos, y moradores...". ${ }^{15}$

El acto de apertura de las sesiones del cabildo explicitaba los valores que sus miembros debían perseguir en el regimiento del gobierno y la administración de la justicia. Para otorgar legitimidad a las reuniones ordinarias y a lo que era tratado y decidido, en el inicio de los acuerdos se apelaba a la costumbre antes que a la ley general y escrita. Esto se corresponde con una concepción del derecho donde las costumbres locales tenían tanto poder como las leyes dictadas desde los órganos centrales de gobierno (Tau Anzoátegui 1992). El hecho de que el acto de apertura y su carácter recordatorio se mantuvieran al menos por dos siglos, de igual manera que el resto de la estructura de las sesiones, nos lleva a preguntamos qué significados y efectos tenía esa continuidad temporal para visualizar el orden social y político precisamente como un orden estable a lo largo de tiempo. Incluso cabe notar que no sólo se apelaba a la costumbre sino que efectivamente se la practicaba y en ello se la constituía como tal al reafirmar su permanencia.

También las elecciones anuales de alcaldes se caracterizaron por un alto grado de formalización. Cada primero de enero el cabildo elegía a dos alcaldes ordinarios y a dos alcaldes de la Santa Hermandad. Estos últimos con voz pero sin voto en el cabildo tenían a su cargo tareas de policía y justicia en la campaña. Las elecciones debían realizarse en las casas capitulares y varias leyes prevenían contra la intrusión de los gobernadores y sus tenientes en la libre elección de los funcionarios ${ }^{16}$. Ciertas acciones y discursos modelaban las elecciones, como la 'bendición' con que el gobernador o su teniente daban inicio al proceso. El 31 de diciembre de 1647 se congregó el cabildo cordobés con la presencia del gobernador, y éste dijo:

que como consta al cab. ${ }^{\circ}$ mañana conforme a la costumbre es dia quando se Eligen al. des y conforme con la obligasion que tiene ss. ${ }^{a}$ como su gov. ${ }^{\text {or }}$ y cap. ${ }^{n}$ g.' les

\footnotetext{
14 Actas Capitulares de Córdoba. Libro IX. Pp. 36.

15 Actas capitulares de Santiago del Estero. Tomo III. Pp. 95.

${ }^{16}$ Véase La Recopilación de Leyes de los Reynos de Indias, Libro IV, Tomo 9.
} 
amonesta pongan la mira de las personas que ubieren de ser elexidos para los tales ofiçios que sean personas selossas del serviçio de [(anbas magestades)] dios nuestro señor y de su mag. ${ }^{d}$ y que miren por el bien de la rrepublica y que la mantengan en pas y en Just. ${ }^{a}$ y que asiendolo asi cumpliran con sus obligaciones y de los contrario les encarga las consiencias y que las dhas Elecssiones las hagan con toda / pas y quietud y que lo que en contrario de esto fuere lo rremediara su ss. ${ }^{a}{ }^{1}{ }^{17}$

Las palabras del gobernador iniciaron el proceso electoral previniendo se hiciera en "paz" y "quietud" y recordando las funciones y los objetivos del cabildo. Reafirmaba los valores que debían guiar el accionar del cuerpo y de sus miembros, y vinculaba la idoneidad de los elegidos con el debido servicio a "ambas majestades". Esta clase apelaciones a la cristiandad (tanto a Dios como a los santos y patronos de las ciudades) deben entenderse en relación con un contexto histórico donde la religión -junto con la moral y el derecho- configuraba un principio regulador de la vida social (Tau Anzoátegui 1999). Las elecciones parecieran haberse constituido en una instancia particular para recordar o reafirmar determinadas normas y valores, potenciando quizá el carácter recordatorio de la apertura de las sesiones ordinarias. Al momento de las elecciones cordobesas en 1656 incluso se incorporaron "las ordenanzas del fundador y se leyeron todas las tocantes a Eleciones y en la forma que se an de hacer"18.

Las elecciones cadañeras de alcaldes pueden ser pensadas a partir del concepto de ritual y como parte del ciclo anual del cabildo, que incluía festejos cívicos y religiosos. Las elecciones marcaban un punto en el año en que el cabildo se reconstituía, salían algunos de sus miembros e ingresaban otros nuevos. Este pasaje se producía en el mismo momento en que se dejaba atrás un año y se iniciaba otro: los nuevos alcaldes eran elegidos el 31 de diciembre y el primero de enero (del año siguiente) hacían el juramento del buen uso de los oficios y se incorporaban en sus cargos.

Desde el momento en que se fundaba una ciudad se instituía el cabildo que regiría su jurisdicción, estando a cargo del fundador la designación de sus primeros miembros. De ahí en más cada año el cabildo sería escenario de un mismo y singular ritual. A través de la lectura de las actas podemos constatar la permanencia de esa celebración, en algunos casos por un período de más de tres siglos. Más allá de esa evidencia fáctica lo que resulta significativo es la importancia que esa continuidad asumía para los propios actores, hecho que se refleja en el caso cordobés cuando se ordenó leer las ordenanzas que estableció el fundador de la ciudad en 1573.

Si repensamos este panorama a partir de los planteos de

\footnotetext{
${ }^{17}$ Actas Capitulares de Córdoba, Libro IX. Pp. 452.

${ }^{18}$ Actas Capitulares de Córdoba, Libro X. Pp. 556. La ciudad de Córdoba fue fundada por Jerónimo Luis de Cabrera en 1573.
}

Leach (1971) sobre las distintas experiencias que engloba la categoría de tiempo, identificamos en el contexto de la institución capitular tres tipos de experiencias que abrigaban las prácticas desarrolladas por sus miembros.

- Repetición: las elecciones anuales se repetían y ellas condensaban en un único acontecimiento el fin de un ciclo y el inicio de otro que sería idéntico al anterior.

- Irreversibilidad: los miembros del cabildo eran efímeros componentes de un cuerpo que permanecía $^{19}$.

- Alternancia: Los individuos integrantes de las facciones o parcialidades locales ocupaban alternadamente los mismos cargos de la institución capitular ${ }^{20}$.

Estas observaciones y la distinción analítica entre estas tres formas de experimentar el tiempo nos llevan a reflexionar sobre el hecho de que esas experiencias que suponían el transcurrir del tiempo fundaban, por el contrario, una noción de permanencia y estabilidad del orden social y en particular, del gobierno municipal. Vale aquí la misma observación que hicimos en el caso de las residencias: cada elección fue en sí misma un hecho único y el conteo lineal (el avance, sin retroceso) de los años es también reflejo de ello. Sin embargo, ese devenir histórico e irrepetible se vio canalizado dentro de los marcos de un mismo ritual por un extenso período de tiempo.

Nuestra interpretación sostiene que la repetición cadañera del mismo ritual -las elecciones- durante siglos tenía implicancias en cómo los protagonistas se representaban el orden social del que eran parte, considerando el hondo pasado en que éste se sostenía y que podía visualizarse -por ejemplo- en la continuidad de las elecciones. Los mismos actores vinculaban en una línea temporal todas las elecciones capitulares, de manera que podía así representarse la vida de un cuerpo

\footnotetext{
19 En 1769 el cabildo santiagueño firmó un contrato con el vecino Balthazar Gaya para que en 20 años realice los arreglos de la acequia. Gaya aclaraba que dicho contrato "con la Señoria del Mui Ilt. ${ }^{e}$ Cavildo Justicia y reg. ${ }^{\text {to" }}$ no lo comprometía solamente con aquellos "Señores" que en ese momento componían el cabildo, sino también "con los q. ${ }^{\mathrm{e}}$ en adelante fueren". Actas capitulares de Santiago del Estero. Tomo III. Pp. 96. Kantorowics (1985) observa que el problema de la perpetuidad del Estado no se resolvía a partir del concepto organológico en sí mismo, pues tomando como figura el cuerpo humano lo estatal sería igualmente terreno y mortal. La inmortalidad del Estado sólo se logra con el concepto de universitas que remite a la idea de "cuerpo" pero ya en un sentido jurídico y filosófico, y abarca "a la «cabeza y miembros» también en sucesión" (1985: 294). Los cuerpos corporativos se proyectan hacia el pasado y el futuro, preservan su identidad en el tiempo, y son inmortales desde la perspectiva jurídica. "La separación de la universitas corporativa de sus componentes individuales, daba como resultado la relativa insignificancia de estos componentes mortales que en cualquier momento dado constituían el colectivo; eran poco importantes si se les comparaba con el cuerpo político inmortal en sí, que sobrevivía a sus elementos constitutivos y podía incluso sobrevivir a su propia destrucción física" (1985: 295).

20 Para un caso paradigmático que escenifica esta dinámica de alternancia en la ocupación de los cargos, véase Boixadós 2004.
} 
político -el cabildo- que trascendía a la de sus propios integrantes y se insertaba como parte de un entramado político-institucional que también se asumía de gran estabilidad. Si nuestra hipótesis es acertada, resultaría entonces que esa dimensión cíclica del tiempo que a su vez asumía un carácter dinámico o de alternancia -la recomposición anual del cabildo- actuaba construyendo la permanencia del cuerpo capitular, y con ello aportaba a una representación más bien estática del mismo.

\section{Desde tiempo inmemorial. Una aproximación a la perspectiva nativa}

Hasta el momento nos detuvimos en el nivel de las prácticas y en particular de aquéllas que se mantuvieron por un lapso prolongado de tiempo. A esto cabe agregar que esa permanencia era valorada positivamente por los propios actores, en tanto legitimaba su accionar presente. Esto surge al estudiar una serie de disputas que mantuvieron los integrantes del cabildo dentro del mismo cuerpo, y éste con otras instituciones políticas y religiosas, donde la fuente de tales controversias residía en el orden de los asientos dentro del cabildo o en celebraciones públicas, el tipo de butaca utilizada, el uso de determinadas insignias o vestimentas, la portación de títulos, entre otros temas. En todos estos casos se trataba de acciones que denotaban y construían el estatus de la persona o la institución, y en ese sentido apelamos al concepto de ritual para focalizar en la dimensión comunicativa o expresiva de la acción; considerando, por supuesto, la capacidad performativa de los actos rituales ${ }^{21}$.

En esta ocasión nos interesa recalar sobre las argumentaciones y los términos utilizados por los actores en la defensa de sus respectivas posturas. Desde esa perspectiva analizamos la disputa que a comienzos del siglo XVIII mantuvieron el cabildo eclesiástico y el deán con el cabildo secular de Córdoba por el lugar que a cada uno le correspondía en el orden de precedencia de las funciones públicas. El ayuntamiento sostenía que los eclesiásticos no debían presidir dichas ceremonias y que tampoco correspondía que se sentaran en sillas en los presbiterios de las iglesias. Como parte del proceso jurídico que llevó este conflicto a la Real Audiencia de Charcas, el arcediano ordenó que se tomara testimonio a varios vecinos de las ciudades de Córdoba y de Santiago del Estero para dar cuenta de cuál había sido comúnmente la práctica estilada, de cómo esa costumbre se alteró y de qué manera actuaron los diferentes cuerpos frente a la controversia 22 . Los declarantes, todos vinculados a la iglesia, se remitieron a sus propias experiencias y ratificaron la postura del arcediano, quien sostenía que el cabildo eclesiástico debía preceder al secular y que los prebendados tenían derecho a sentarse en sillas en

\footnotetext{
21 Sobre el concepto de ritual véase nota 2 .

22 La Iglesia Catedral residió en Santiago del Estero hasta que 1699 fue trasladada a Córdoba.
}

los presbiterios. Relataron diversas situaciones en que participaron o de las cuales fueron testigos, y que daban cuenta de que así se habían desarrollado las festividades o actos públicos en que concurrían autoridades seculares como eclesiásticas. En esa tónica don Juan Ordoñez del Aguila que vivó en Santiago del Estero durante la época en que allí residía la catedral, confirmó los dichos del arcediano. Incluso dada su familiaridad con algunos funcionarios eclesiásticos "le consta que el estilo que vio era en conformidad de posesión inmemorial sin que jamás hubiese habido en ello innovación ni contradicción ni reparo alguno"23. Otro de los declarantes sostuvo que "era estilo y costumbre" que los prebendados se sentaran en sillas en los presbiterios de las iglesias y que fueran por delante del cabildo secular en las procesiones, y así "estando en esta posesión quieta y pacífica" refirió que fue el gobernador Thomas Felix de Argandoña quien "intentó perturbarla e innovar el estilo"24.

La casuística de estas argumentaciones se inscribía en la lógica propia del derecho indiano, que se nutría de la ley general, la costumbre local y la doctrina de los autores. Se trataba de un derecho que se acomodaba a los pueblos, regiones y contextos diversos que caracterizaban a las colonias indianas, y que habilitaba el incumplimiento de la ley o de las órdenes reales si éstas no se correspondían con las costumbres locales (Tau Anzoátegui 1992 y 2001). Esto quiere decir que esa apelación a la costumbre o al tiempo inmemorial a la que recurrían los actores locales, se veía también amparada o impulsada por la autoridad y la legislación regia.

En el pleito que mantuvo el cabildo de Córdoba con el teniente general y justicia mayor de la ciudad, don Bartolomé de Ugalde, también encontramos algunos de esos términos. El problema giraba en torno a los contextos en los cuales ese funcionario debía portar la vara de justicia. Se trataba de una insignia de jurisdicción que confería autoridad a quienes la ostentaban y se convertía en un medio a través del cual dichos funcionarios eran reconocidos públicamente en sus $\operatorname{cargos}^{25}$. Ugalde argumentaba que la práctica usual era que el teniente general usara vara alta en los acuerdos del cabildo y bastón en las funciones públicas. Por su parte, el cabildo le exigía que llevara vara alta en ambas clases de concursos. Ugalde fundamentaba su postura diciendo que ésa había sido la costumbre local y que así lo habían seguido sus predecesores, y por tanto el problema residía en "haberse alterado, e innovado la referida costumbre inmemorial por los dichos señores" 26 . Para dar testimonio de ello mandó se consultara a varios testigos, seis hombres de un promedio de 65 años, todos los cuales

\footnotetext{
${ }^{23}$ Archivo y Biblioteca Nacional de Bolivia, Sucre. Expedientes Coloniales 1710.20 , f. 17 .

24 ABNB. EC 1710-20, f. 19v-20v

25 Sobre la vara, véase Bayle (1952) y Bravo Lira (1983).

${ }^{26}$ ABNB. EC 1714-55, f. 13r-13v.
} 
confirmaron sus dichos y acusaron al cabildo de haber innovado la costumbre local.

En estos dos casos -igual que en otras controversias que examinamos- se registran una serie de términos tales como estilo, costumbre inmemorial, tiempo inmemorial, práctica y en oposición encontramos otros como innovar o alterar. Apelar a las primeras categorías servía para otorgar legitimidad a la práctica que el sujeto estaba defendiendo ${ }^{27}$. Es decir, la legitimidad de una práctica al menos en parte se constituía a partir de su permanencia y su inalterabilidad en el tiempo. Por ejemplo, en un enfrentamiento que en el año 1719 tuvo el cabildo cordobés con un Alcalde provincial de la Santa Hermandad por el lugar que a éste le correspondía en el orden de los asientos, los capitulares se retrotrajeron hasta el momento de fundación de la ciudad y expusieron las actas de los acuerdos donde constaba la costumbre observada desde hacía casi un siglo ${ }^{28}$.

En ese caso nuestro interés no reside en datar los años efectivos de permanencia de una costumbre, sino en tratar de entender a partir de qué criterios ésta podía asumirse como legítima y practicarse ${ }^{29}$. El análisis de los significados y del uso contextuado de términos como costumbre o tiempo inmemorial nos llevan a preguntarnos por las nociones de orden y de tiempo que están implicadas en los mismos, puesto que observamos justamente que el pasado en tanto visualizado como un orden estable y permanente asumía un rol central en la perspectiva de estos actores para establecer la legitimidad de una práctica en su 'presente'. Lo que también registramos es una recurrente oposición de sentidos entre innovar/ perturbar y tradición/ costumbre/ tiempo inmemorial. Parece producirse incluso una asimilación entre innovar y perturbar (las costumbres). Considerando estas observaciones, puede interpretarse que desde la perspectiva nativa la novedad que suponía la introducción de un cambio era percibida como una perturbación; y aquello que se perturbaba sería el orden

\footnotetext{
27 O'Phelan Godoy a través de un estudio de casos (conflictos por posesión de tierras, sucesiones cacicales, prácticas rituales y contribuciones en tiempo y dinero dictadas por la costumbre) analiza en particular el uso de la noción de "tiempo inmemorial" como recurso al que se apelaba para legitimar la práctica o postura defendida.

28 ABNB. EC 1732-23.

29 Según O'Phelan Godoy, hacia fines del período colonial la noción de tiempo inmemorial podía a lo sumo retrotraerse al período tardío de los Habsburgo, de forma que en su uso se apelaba a ella para oponerse a las nuevas medidas impulsadas por el programa borbónico. La comparación del trabajo de O'Phelan Godoy con las fuentes que analizamos (comprendidas en un espectro temporal más amplio) nos sugiere la pregunta por las transformaciones que la noción de tiempo inmemorial pudo haber sufrido: ¿a qué período, años, acontecimientos o cantidad de generaciones remitía la categoría de tiempo inmemorial a comienzos del siglo XVIII? ¿y a qué otros elementos (si acaso no a los mismos) a fines del período colonial? No contamos con los datos para responder a esta pregunta, pero sí cabe dejar planteado que en las fuentes trabajadas hasta el momento un acontecimiento recurrente asociado al tiempo inmemorial es el momento de fundación de la ciudad.
}

establecido, la tradición y la costumbre. Es decir, la valoración positiva de la permanencia, de la estabilidad o en términos nativos de la costumbre inmemorial hallaría su contrapartida en la valoración negativa del cambio y la novedad, entendidos como innovación o perturbación de ese orden establecido. En ese sentido no resulta extraño que en el período tardío colonial, como observa O’Phelan Godoy, "el reclamo a respetar la tradición será, de alguna manera, el juego de palabras que se oponga a los elementos modernizantes que cargaba dentro de sí el programa borbónico" (1993: 3).

\section{El tiempo como problema}

Como dijimos en la introducción, este artículo constituye un puntapié para sistematizar una serie de interrogantes con respecto al problema del tiempo en la constitución y representación del orden colonial y para evaluar, a través del examen de un conjunto fuentes documentales, si resulta viable y qué nuevas aristas iluminaría abocarnos a desandar alguna de esas múltiples preguntas que hemos elaborado.

Habiendo reconocido en términos teóricos la ligazón que existe entre el orden de las prácticas y la representación y experiencia del tiempo, entendemos que en nuestro caso la comparación entre las rutinas del cabildo y la reacomodación de actividades que suponía la residencia constituye una veta para analizar las características singulares en que se vivenciaba el tiempo cotidiano y el tiempo interno de ese proceso ritual. Es decir, se trata de dos tipos de prácticas distintas cuyos tiempos parecen haber asumido también formas diferentes. La clase de fuentes con que trabajamos plantea limitaciones para indagar en esta problemática, puesto que justamente la formalidad de las actas o el expediente jurídico de la residencia comprimen en sus moldes gran parte de la experiencia y la agencia de los actores. Inferimos que el despliegue de la residencia en tanto un ritual regio que marcaba la configuración del orden político en una escala más amplia, perturbaba el decurso cotidiano de la ciudades, pero ¿cómo lo vivenciaban sus habitantes de manera concreta? Y ¿en qué consistían esos murmullos, conversaciones o negociaciones 'privadas', miradas desconfiadas, que se nos presentan tan 'obvias' en nuestra imaginación histórica (fundada en la investigación que venimos desarrollando) pero a las cuales no podemos acceder desde la mediación que nos imponen los documentos trabajados hasta el momento?

Por otro lado, entendemos que esa rigidez de la estructura de las residencias y la persistencia de los cabildantes en adecuarse a fórmulas y discursos tan tradicionales pueden asumir a la luz de una aproximación etnográfica otros sentidos que no los relegan a una simple "sobrevivencia" de etapas pasadas. Estas observaciones apuntan la necesidad de investigar el problema del tiempo atendiendo a la continuidad impuesta por las instituciones 
analizadas y a la significación que los actores le otorgaban a su permanencia. El interés reside en comprender en qué medida y cómo el carácter estable de estas instituciones contribuía a elaborar una imagen del orden social anclado en un tiempo extenso, un tiempo inmemorial, o un presente que debía permanecer fiel al pasado. Pareciera que el cambio se frenara y que la historia se detuviera. El problema se enfoca hacia cómo estos actores pensaban y construían sus representaciones del orden social en relación con una determinada representación del tiempo, y más aún de su propia historia.

Por supuesto con ello no estamos diciendo que en los hechos no hayan ocurrido tales transformaciones. Incluso esto nos permite introducir un tercer problema. Recuperando los aportes de Sahlins (1988) con respecto a las relaciones entre cultura e historia, nos preguntamos cómo los cambios eran significados desde el prisma de una cultura que a nivel de ciertas prácticas y representaciones, pareciera haberlos negado o al menos que proclamaba la estabilidad y la permanencia de las instituciones. Esto se complejiza cuando por un lado, advertimos la capacidad de los rituales para otorgar a los valores sociales y a las creencias transmitidas un carácter de permanencia, de tradición o inmutabilidad (Tambiah 1985, Falk Moore y Myerhoff 1977); mientras que por otro lado, en el caso de los cabildos observamos que esa noción de estabilidad pareciera haberse construido a través de un conjunto de prácticas que anidaban una experiencia del tiempo dinámica (irreversible, cíclica y alternante).

Un cuarto problema reside en profundizar el análisis sobre la manera en que esos tiempos que se construían a partir de los cabildos y las residencias se articulaban con los diversos espacios y jurisdicciones sobre los que actuaban y los cuerpos sociales que también contribuían a delimitar. Estas dos instituciones operaban en distintas escalas del entramado político-institucional indiano y ello nos permite advertir la configuración de un orden social que era impuesto desde los órganos más centralizados de la monarquía y también construido a través de las prácticas concretas de la institución capitular.

Por último, así como distinguimos en nuestro análisis tiempos diversos nos preguntamos si también es posible hablar de más de una historicidad. Si conceptualizáramos el expediente de la residencia y los archivos del cabildo como memorias de la sociedad en que se elaboraron, ¿en qué coordenadas espacio-temporales cada historia fue concebida? ¿cuáles eran sus protagonistas y a qué agregado corporativo pertenecían?, ¿podríamos referirnos a una historicidad construida desde los órganos centrales frente otra desarrollada desde las instituciones locales? Estas preguntas nos devuelven igualmente a reflexionar sobre cómo estos órdenes que analíticamente distinguimos se entrelazaban en la práctica y la perspectiva de los actores, considerando que los vecinos y funcionarios locales eran partícipes interesados en la elaboración de ambos registros documentales.

Buenos Aires, 15 de junio de 2010

\section{Agradecimientos}

Agradezco a la Dra. Roxana Boixadós la lectura crítica y atenta que realizó sobre distintas versiones del trabajo, y por darme la oportunidad de discutir con ella el análisis y las preocupaciones que exploro en el mismo.

Agradezco también a los evaluadores anónimos por sus valiosos comentarios y sugerencias.

\section{Fuentes}

\section{Éditas}

Actas Capitulares de Córdoba, Libro IX: 1643-1650. 1952. Archivo Municipal de Córdoba.

Actas Capitulares de Córdoba. Libro X: 1650-1661. 1952. Archivo Municipal de Córdoba.

Actas capitulares de Santiago del Estero, Tomo III. Años: 1767-1777. 1946. Buenos Aires, Academia Nacional de la Historia, Guillermo Kraft Ltda.

\section{Inéditas}

Archivo Histórico Nacional, Madrid, España.1775-1776. Residencia de Juan Manuel Campero, Gobernador de Tucumán. Consejos, 20373, expediente 1.

Archivo y Biblioteca Nacional de Bolivia (ABNB), Sucre. Expedientes Coloniales (EC) 1672-15. Expediente seguido por el señor fiscal sobre que se saque a un nuevo remate el oficio de Alcalde Provincial de la Ciudad de la Rioja en el Partido de Buenos Aires, por haber desamparo el que hizo Don Joseph Sanchez de Loria; y a posesión hecha por este.

ABNB, Sucre. EC 1710-20. Reclamación del Cavildo Eclesiástico de Córdova, sobre el lugar que debe tener el Cabildo Secular, en las asistencias de tabla.

ABNB, Sucre. EC 1714-55. Dn. Bartolomé de Ugalde, Teniente Gral. Y Justicia Mayor de Córdova, sobre el derecho usar bastón y vara alta y presidir las funciones públicas.

ABNB, Sucre. EC 1732-23. Dn. Miguel Esteban de Goyochea, Alcalde Mayor de Jujuy, sobre el asiento que debe ocupar en el Cabildo.

Recopilación de Leyes de los Reynos de Indias. 1681. Archivo Digital de la Legislación en el Perú. Congreso de la República del Perú. http://www.congreso.gob.pe/ ntley/LeylndiaP.htm 


\section{Bibliografía}

Bascary, A. M. 1997. La saga de los Villafañe: una red familiar en el Tucumán Colonial. Andes, 8: 175-198.

Bayle, C. 1952. Los cabildos seculares en la América española. Sapiente S.A. Ediciones, Madrid.

Boixadós, R. 1997. Herencia, descendencia y patrimonio en la Rioja colonial. Andes, 8: 199-224.

Boixadós, R. 2004. Asuntos de familia, cuestiones de poder: la "concordia" en el Cabildo de La Rioja, Gobernación del Tucumán, 1708. Colonial Latin American Historical Review, 13 (2): 147-171.

Bravo Lira, B. 1983. Símbolos de la función judicial en el derecho indiano. Poder y presión fiscal en la América Española (siglos XVI, XVII y XVIII). Trabajos del VI Congreso del Instituto Internacional de Historia del Derecho Indiano: 235-254. Instituto Internacional de Historia del Derecho Indiano, Valladolid.

Bridikhina, E. 2007. La ciudad y la corte como espacios de poder en Hispanoamérica. La Plata colonia". Revista de Indias, LXVII (240): 553-572.

Cañeque, A. 2004. The king's living image: the culture and politics of viceregal power in Colonial Mexico. Routledge, Nueva York.

De la Orden de Peracca, G. 2001. Familia y poder en Catamarca colonial. Los Nieva y Castilla (1630-1730). Memoria Americana, 10: 95-138.

Díaz Cruz, R. 1998. Archipiélago de rituales: teorías antropológicas del ritual. Anthropos, México.

Durkheim, É. 2007. Las formas elementales de la vida religiosa. Akal, Madrid.

Durkheim, É. y M. Mauss. 1971. De ciertas formas primitivas de clasificación. Contribución al estudio de las representaciones colectivas. Mauss, M., Instituciones y culto. Obras II: 13-73. Barral, Barcelona.

Evans-Pritchard, E. E. 1979. Los Nuer. Anagrama, Barcelona.

Falk Moore, S., B. Myerhoff. 1977. Introduction: Secular Ritual: Forms and Meanings.

Falk Moore, S. F. y B. G. Myerhoff (edit.), Secular ritual: 151-172. Van Gorcum, Holanda.

García Valdeavellano, L. 1963. Las «Partidas» y los orígenes medievales del juicio de residencia. Boletín de la Real Academia de la Historia, 153 (cuaderno 11): 205-246.
Garriga, C. 1991. Control y disciplina de los oficiales públicos en Castilla: la "visita" del Ordenamiento de Toledo (1480). Anuario de historia del derecho español, 61: 215-390.

González Alonso, B. 1978. El juicio de residencia en Castilla, I: origen y evolución hasta 1480. Anuario de historia del derecho español, 48: 193-247.

Goody, J. 1961. Religion and Ritual: The Definitional Problem. The British Journal of Sociology, 12 (2): 142-164.

Guevara Gil, A., F. Salomon. 1994. A "personal visit": Colonial political ritual and the making of Indians in the Andes. Colonial Latin American Review, 3 (1-2): 3-36.

Herzog, T. 2000. Ritos de control, prácticas de negociación: pesquisas, visitas y residencias y las relaciones entre Quito y Madrid (1650-1750). Fundación Histórica Tavera, Madrid.

Jiménez Núñez, A. 1997. El juicio de residencia como fuente etnográfica: Francisco Briceño, gobernador de Guatemala (1565-1569). Revista Complutense de Historia de América, 23: 11-21.

Kantorowics, E. H. 1985. Los dos cuerpos del rey. Un estudio de teología política medieval. Alianza Editorial, Madrid.

Leach, E. 1976. Sistemas políticos de la Alta Birmania. Estudio sobre la estructura social Kachin. Anagrama, Barcelona.

Leach, E. 1971. Dos ensayos sobre la representación simbólica del tiempo. Leach, E., Replanteamiento de la antropología: 192-210. Seix Barral, Barcelona.

Lorandi, A. M. 2000. Las residencias frustradas. El juez Domingo de Irazusta contra el Cabildo de Salta. Andes, 11: $51-80$.

Lorandi A. M., S. Smietniansky. 2004. "La conspiración del silencio. Etnografía histórica de los cabildos del Tucumán colonial (1764-1769)". Jahrbuch Für Geschichte Lateinamerikas, 41: 65-90..

Marchionni, M. 1999. Una élite consolidada. El cabildo de Salta en tiempos de cambios. Mata de López, S. (comp.), Persistencias y cambios: Salta y el Noroeste argentino. 1770-1840, 177-218. Prohistoria \& Manuel Suárez, Salta.

Mariluz Urquijo, J. M. 1952. Ensayo sobre los Juicios de Residencia indianos. Escuela de Estudios Hispanoamericanos, Sevilla.

Mata de López, S. 2001. Familias de elite en Salta a fines de la colonia. Negocios y relaciones de poder. Memoria 
Americana, 10: 139-175.

O'Phelan Godoy, S. 1993. Tiempo inmemorial, tiempo colonial: un estudio de casos. Procesos, Revista Ecuatoriana de Historia, 4: 3-20.

Ortemberg, P. 1999. "Celebraciones del poder real en Lima: simbolismo y poder en el mundo urbano colonial". Facultad de Filosofía y Letras, Universidad de Buenos Aires, Argentina.

Osorio, A. 2008. Inventing Lima. Baroque Modernity in Peru's South Sea Metropolis. Palgrave Macmillan, Nueva York.

Paz, G. 1997. Familia, linaje y red de parientes: la élite de Jujuy en el siglo XVIII. Andes, 8: 145-174.

Peirano, M. 2001. A análise antropológica de rituais. Peirano, M. (org.), O dito e o feito. Ensaios de antropología dos rituais: 17-40. Relume Dumará, Río de Janeiro.

Phelan, J. L. 1995. El Reino de Quito en el siglo XVII. Banco Central del Ecuador, Quito.

Ponce, M. 1985. El control de la gestión administrativa en el Juicio de Residencia al Gobernador Manuel González Torres de Navarra. Academia Nacional de la Historia, Caracas.

Ponce, M., L. Vaccari de Venturini (comp). 1980. Juicios de Residencia en la Provincia de Venezuela. Tomo II: Juan Pérez de Tolosa y Juan de Villegas. Academia Nacional de la Historia, Caracas.

Saguier, E. 1992. La lucha contra el nepotismo en los orígenes de las reformas borbónicas. La endogamia en los cabildos de Salta y Tucumán (1760-1790). Andes 5.

Sahlins, M. 1988. Islas de Historia. La muerte del Capitán Cook. Metáfora, Antropología e Historia. Gedisa, Barcelona.

Smietniansky, S. 2007. El juicio de residencia como ritual político en la colonia (Gobernación de Tucumán, siglo XVIII). Memoria Americana 15: 71-101.

Smietniansky, S. 2009. La dimensión ritual del poder en el gobierno del Tucumán colonial (siglos XVII y XVIII). Un enfoque antropológico. Tesis de maestría. Instituto de Altos Estudios Sociales, Universidad Nacional de General San Martín, Argentina, páginas 174.

Smietniansky, S. 2010. Celebrando el orden social, inquietando el orden ritual. Un análisis en clave ritual sobre usos, conflictos e intereses encontrados durante un juicio de residencia en el Tucumán colonial. Andes, 21. En prensa.

Tambiah, S. 1985. Culture, thought and social action. Harvard University Press, Cambridge.

Tau Anzoátegui, V. 1992. La ley en América Hispana. Del Descubrimiento a la Emancipación. Academia Nacional de la Historia, Buenos Aires.

Tau Anzoátegui, V. 1999. Introducción; La Monarquía. Poder central y poderes locales; Órdenes normativos y prácticas socio-jurídicas. La justicia. Nueva Historia de la Nación Argentina. Tomo II: La Argentina en los siglos XVII y XVIII. Pp.: 9-18, 211-250 y 283-316. Academia Nacional de la Historia y Editorial Planeta, Buenos Aires.

Tau Anzoátegui, V. 2001. El poder de la costumbre. Estudios sobre el Derecho Consuetudinario en América hispana hasta la Emancipación. Instituto de Investigaciones de Historia del Derecho, Buenos Aires.

Thompson, E. 1984. Tradición, revuelta y conciencia de clase. Grijalbo, Barcelona.

Todorov, T. 1982. La conquista de América. La cuestión del otro. Siglo XXI, México.

Torres Arancivia, E. 2006. Corte de Virreyes. El entorno del poder en el Perú del siglo XVII. PUCP - Fondo Editorial, Lima.

Turner, V. 1999. La selva de los símbolos. Aspectos del ritual ndembu. Siglo XXI, México.

Vaccari de Venturini, L. 1974. Evolución de los juicios de residencia en Venezuela (Siglos XVI-XVIII). Academia Nacional de la Historia, Caracas.

Zorraquín Becú, R. 1956. Los cabildos argentinos. Imprenta de la Universidad. 
